\title{
Atypical Mycobacterial Infection in A Diabetic Patient: A Case Report
}

\author{
Islam $\mathrm{S}^{\mathrm{a}}$, Begum $\mathrm{HA}^{\mathrm{b}}$, Ripa $\mathrm{AN}^{\mathrm{c}}$, Hoque $\mathrm{SZ}^{\mathrm{d}}$, Ahmed $\mathrm{AU}^{\mathrm{e}}$
}

\begin{abstract}
:
Atypical mycobacteria are opportunistic, acid-fast and ubiquitous organisms. It is not uncommon in our society and is usually acquired from environmental sources like water and soil. Immunocompromised patients are prone to develop this infection. Many cases with similar and additional features have been reported in foreign literature. We describe one case of this infection along with review of literature.

This is a 45 year old Bangladeshi diabetic woman, who was referred from department of general surgery for non- healing cutaneous abscess in the left lower abdomen. The patient underwent surgical drainage with empirical antibiotic coverage. But as the lesions were not healing she was referred to Dermatology. After having clinical suspicion, biopsy was taken and histological examination revealed tuberculoid granulomas and in tissue culture M.fortuitum was isolated. Although M.fortuitum was resistant to commonly used antitubercular drugs but it was found sensitive to amikacin, clarithromycin and ethambutol. Combination of these drugs later proved to be successful.
\end{abstract}

Keywords: Atypical mycobacterial infection, Mycobacterium fortuitum, rapid grower, immunocompromised.

(BIRDEM Med J 2017; 7(1): 68-71)

\section{Introduction}

Atypical mycobacteria infection are infections caused by a species of Mycobacteria other than M.tuberculosis and M.leprae causing pulmonary and extrapulmonary tuberculosis and Hansen's disease. The mode of presentation of infection of Atypical Mycobacteria is enormously varied. These are facultative pathogens and saprophytes which are acid fast mycobacteria. They exist in a wide variety of natural sources such as

\section{Author Informations}

a. Sabrina Islam, Department of Dermatology and Venereology, BIRDEM Hospital, Dhaka

b. Hosne Ara Begum, MBBS, DDV, FCPS, Fellow in Dermatosurgery, Associate Professor, Department of Dermatology and Venereology, BIRDEM hospital; Dhaka

c. Arifun Nahar Ripa, DDV student, Department of Dermatology and Venereology, BIRDEM Hospital, Dhaka

d. Shah Zobaid-Ul Hoque, MBBS, MRCP (UK), Specialist, Department of Nephrology, Square Hospitals Ltd, Dhaka

e. Ashraf Uddin Ahmed, MBBS, FCPS (Medicine), Specialist, Department of Internal Medicine, Square Hospitals Ltd, Dhaka

Address of correspondence: Dr. Sabrina Islam, Department of Dermatology and Venereology, BIRDEM General Hospital,Dhaka, Bangladesh. Email: sabrinazafeer@gmail.com

Received: November 22, 2016 Accepted: November 30, 2016 soil, water, and animals. M.fortuitum and M. chelonae strains also known as the rapidly growing organisms having implicated in wound, soft tissue, pulmonary and middle ear infection. Disease in patients who are immunocompetent usually consist of localized skin and soft tissue infection. This infection can also be introduced after surgery and through contaminated injections, surgical canulations, trauma as because atypical mycobacteria do not have the ability to pass through the intact mucus membrane or skin. Diabetes Mellitus ,Pulmonary emphysema, Leukaemia, Collagen Vascular disease, Chronic kidney disease, Lung cancer and Acquired immune deficiency syndrome(AIDS) may predispose to Non tubercular mycobacterial infections (NTMB). The disease is progressive and fatal if untreated. Prompt recognition and appropriate treatment helps in complete recovery of the patients.

\section{Case report}

A 45 year old Bangladeshi diabetic lady who is a housewife, presented with the complains of multiple painful erythematous nodular lesions over the left lower 
abdomen for the last 1 month. The nodules were 3-5 $\mathrm{cm}$ in size. Linear sclerotic scar marks were present in the lower abdomen from previous surgical drainage of the nodules. On examination the nodules were tender and firm in consistency and one of them have purulent discharge. Regional lymph nodes are not enlarged. She also complained of low grade fever in the evening but was not associated with chills and rigor. Investigation revealed, on complete haemogram there was leucocytosis 13000/cmm ( Ref range 4000-11000) and

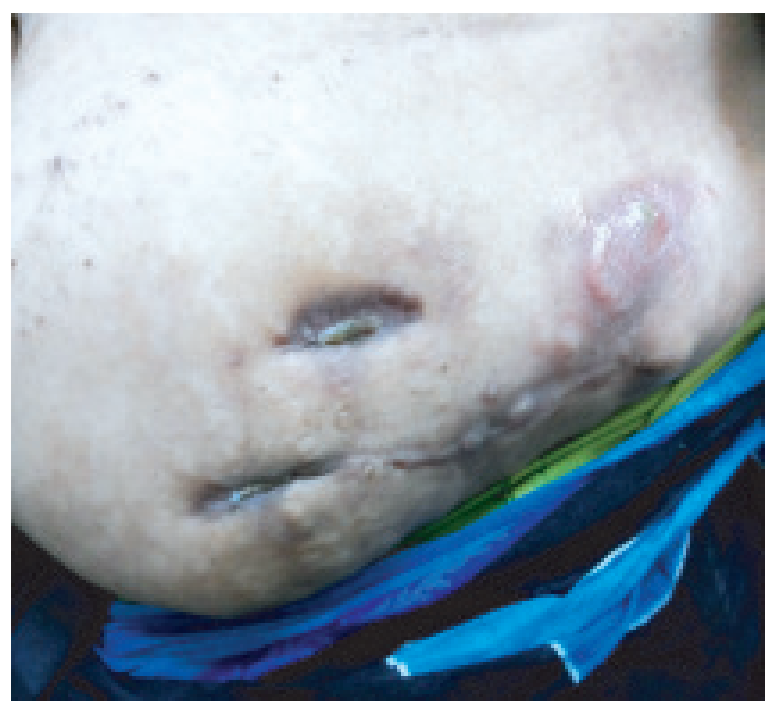

Figure 1: At presentation
ESR $36 \mathrm{~mm}$ in $1^{\text {st }}$ hour. Zheil Nelson staining : Acid fast bacilli is present. $\mathrm{X}$ ray chest $\mathrm{P} / \mathrm{A}$ view shows no abnormality. Mantoux test is Negative .

Tissue culture shows growth of non tubercular mycobacteria rapid grower- M.fortuitum. Antibiogram shows sensitivity to Amikacin, Ciprofloxacin, Linezolid, Clarithromycin and Ethambutol.

Histopathology report reveals section of the skin shows polymorphonuclear leucocyte microabscesses and granuloma fromation with foreign body type giant cell in the dermis. Acid fast bacilli is found within microabscesses. No caseation is found. Features suggestive of atypical mycobacteria.

The case was diagnosed as Atypical Mycobacteria infection ( Rapid growers- M.fortuitum ) by history, clinical features, clinical examinations and laboratory findings. The case was treated initially by Injection Amikacin $250 \mathrm{mg}$ twice daily for 2 weeks and Tablet Ethambutol $400 \mathrm{mg} 2$ tablets daily for 2 weeks. After further improvement injectable Amikacin was replaced by Tablet Clarithromycin $500 \mathrm{mg}$ bid. Then the combination of ethambutol and clarithromycin was continued for 6 months during which patient was monitored monthly and was cured completely.

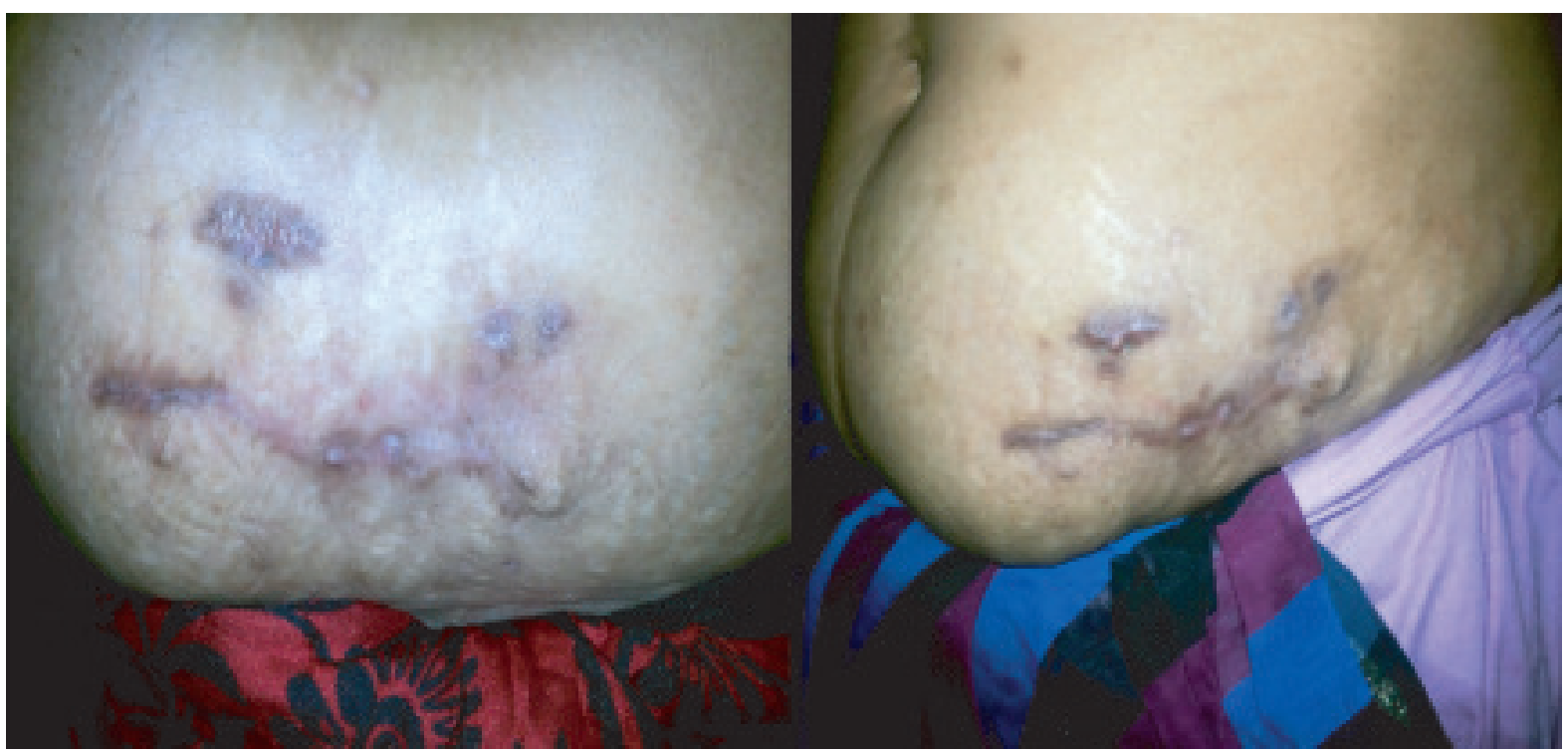

Figure 2: After 2 months of treatment

Figure 3: After 6 months of treatment 
Table-I. Common Atypical Mycobacterium species and notable sites of infection

\begin{tabular}{|c|c|c|}
\hline Organism & Common site of infection & Less common \\
\hline Slow growing & Pulmonary & Skin \\
\hline M.avium complex & Dissemination $^{\mathrm{a}}$ & \\
\hline \multicolumn{3}{|l|}{ Lymphadenitis } \\
\hline M. genavense & Dissemination $^{\mathrm{a}}$ & Pulmonary $^{\mathrm{a}}$ \\
\hline \multicolumn{3}{|l|}{ Gastrointestinal $^{\mathrm{a}}$} \\
\hline Lymphadenitis( cervical) & Intraocular & \\
\hline M.haemophilum & Skin & \\
\hline \multicolumn{3}{|l|}{ Pulmonary } \\
\hline \multicolumn{3}{|l|}{ Dissemination $^{\mathrm{a}}$} \\
\hline \multicolumn{3}{|l|}{ Bone and joint } \\
\hline M. kansasii & Pulmonary & Lymphadenitis \\
\hline Dissemination $^{\mathrm{a}}$ & Skin & \\
\hline M.leprae & Skin Lymphadenitis & \\
\hline \multirow[t]{4}{*}{ M.malmoense } & Pulmonary & Lymphadenitis \\
\hline & Skin & \\
\hline & Bone and joint & \\
\hline & Dissemination & \\
\hline \multirow[t]{3}{*}{ M.marinum } & Skin & Joint space \\
\hline & Lymphadenitis & \\
\hline & Dissemination ${ }^{1}$ & \\
\hline Lymphadenitis(cervical) & Pulmonary & \\
\hline \multirow[t]{2}{*}{ M.scrofulaceum } & & Skin \\
\hline & Dissemination $^{\mathrm{a}}$ & \\
\hline M.ulcerans & Skin & Dissemination $^{\mathrm{a}}$ \\
\hline \multirow[t]{3}{*}{ M.xenopi } & Pulmonary & Joint space \\
\hline & Lymphadenitis & \\
\hline & Dissemination $^{\mathrm{a}}$ & \\
\hline Rapid growing & & Skin \\
\hline \multirow[t]{2}{*}{ M.abscessus } & Pulmonary & Catheter related \\
\hline & Dissemination & \\
\hline M.chelonae & Skin & Pulmonary \\
\hline \multicolumn{3}{|l|}{ Bone and joint } \\
\hline \multicolumn{3}{|l|}{ Catheter related } \\
\hline M.fortuitum & Skin & Pulmonary \\
\hline \multirow[t]{3}{*}{ Catheter related } & Lymphadenitis & \\
\hline & Ophthalmological & \\
\hline & Bone and joint & \\
\hline
\end{tabular}

aPrimary opportunistic infection in patients with severe immunodeficiency ( i.e HIV, haematological malignancy and bone marrow transplantation)

\section{Discussion}

Atypical mycobactria may cause different types of infections, which are divided into the following four clinical syndromes:

Pulmonary disease

Lymphadenitis

Skin and soft tissue infection

Disseminated disease
Skin infection tends to result in crusted nodules and plaques and abscess.

There are many different species of atypical mycobacteria. To date at least 30 mycobacteria that do not cause TB or leprosy are noted (Table - I)

M.fortuitum has world wide distribution found in natural and processed water sources, sewage and dirt. Often the cause of operated wound infection in surgical site is 
from contaminated water sources. It causes a non healing ulcerated skin lesions and /or sub cutaneous crusted nodules. Atypical MTB are diagnosed on tissue culture on specific conditions, such as cool temperature. The infection has specific pathological features on skin biopsy. Other diagnostic tools used include radiographic imaging studies and more recently PCR test on swabs of ulcers or tissue biopsies. ${ }^{1}$

The treatment of Atypical MTB infection depends on the infecting organism, severity of infection and resistance to antibiotics. The antimicrobial agent's amikacin, clarithromycin, which are not conventionally considered for use in treatment of Mycobacterium infection inhibit the growth of M.fortuitum in localized infection. Better results shows if used in adjunct with surgical debridement. Disseminated infection requires combination treatment using a macrolide, aminoglycoside and antitubercular drug. ${ }^{2}$ Most lesions eventually heal after 6-9 months but may leave behind extensive scarring and disfigurement. ${ }^{3}$ Skin grafting is necessary in some cases to repair surgical wound.

\section{Conclusion}

Although the pathogenesis, epidemiology, disease status and clinical presentation of atypical mycobacterial infection are quite diverse, a common characteristic is their challenging pharmacotherapeutic management. The prolonged duration of antimicrobial therapy , variable response rates to therapy and the pharmacological characteristics of the drugs involved, place tremendous responsibilities on the clinician to manage compliance, adverse effects and drug interaction while ensuring that the patient's condition is improving and the infection is being effectively treated.

\section{Conflict of Interest : None}

\section{References}

1. Bartralot R, García-Patos V, Sitjas D, Rodríguez-Cano L, Mollet J, Martín-Casabona N, et al. Clinical patterns of cutaneous nontuberculous mycobacterial infections. Br J Dermatol 2005: 727-34.

2. Wallace RJ, Glassworth J, Grifith DE, Oliver KN, Cook JL, Gordon F, Diagnosis and treatment of disease caused by nontubercular mycobacteria. Am J Respiscrit Care Med 1997; 156 (suppl) : S1-S25

3. Atypical mycobacterial infection. A case report. Gulf Medical Journal, ASM 2015; 4(S1): S149-S154 